\title{
원조사업 성과관리의 개요 및 동향 \\ : AFD의 사례를 중심으로
}

\section{목 차}

I. 서론

II. 결과 중심 성과 관리

III. 공적 원조 사업에 있어서의 성과관리

IV. 프랑스의 $A D F$ 의 성과관리 사례

V. 결론 및 제언

\section{I. 서론}

원조 사업에 있어서 성과관리는 자원의 효율적인 활용이라는 점에서 매우 중요한 일이나, 공공부분 과 해외 현장이라는 특수성으로 인해 큰 어려움을 겪고 있는 분야 중 하나이다.

결과 중심의 성과 관리는 새로운 개념의 등장이라기보다 공공부분의 사업 관리로 인해 점진적인 발전 과정 중에 놓인 사업의 특성 및 형태 변화에 따라 끊임없이 변하는 개념으로 70년대와 80년대, 서구 사회를 중심으로 일어났던 경기침체와 더불어 공공부분의 확장이 공공기관들 운영에 비효율적 이라는 비판에 따라 처음 도입 되었다. 공공기관은 사기업과는 달리 이윤을 목적으로 하지 않으므로, 기관의 성과를 정의하기 힘든 면이 많아 주로 결과 보다는 사업 과정, 즉 투입물input과 사업 행위 activity에 치중하고 있었다. 그러나 이러한 사업 과정 중심의 성과관리는 오히려 사업 진행에 방해 가 되는 관료주의적 제도를 고착화 시키고, 업무의 비효율을 조장하는 장애 요소임이 확인되었다. 따 라서 안으로는 공여기관을 포함한 모든 공공기관이 국민과 국민을 대표하는 의회에 그 투명성과 효 과성을 증명해야 할 필요가 커졌으며, 밖으로는 원조의 효과성과 책무성을 밝히기 위해 보다 효율적 인 관리 제도의 도입이 필요하였기에 결과 중심의 성과관리가 탄생하게 되었다. 90 년대를 거치면서 미국, 캐나다, 호주 등 서구 선진국들이 모든 정부·공공 부분에 있어서 결과중심의 성과관리 제도를 
도입하였으며 이는 공적 원조 기관들도 예외가 아니었다. 그리고 2000년대 중반, 파리 선언과 함께 공적 원조 기관에서의 결과중심의 성과관리는 개발 결과를 위한 성과 관리(Management for Development Results)로 재조명되었다.

이 논문은 성과관리에 전반적으로 접근하고 그 중 사업 평가의 역할을 수립하기 위해 2011년 8월 개 최되었던 평가 세미나의 결과물이다. 이 논문을 통해 사업 성과관리의 개념을 정리하고, 선진 원조기관 중의 하나이며 $\mathrm{KOICA}$ 와 같이 정책과 시행 기관으로 분리된 형태의 원조기구를 갖춘 프랑스의 $\mathrm{AFD}$ 의 사례를 통해 앞으로 한국 국제 협력단의 사업 성과관리가 나아갈 방향에 대한 제언을 도출하고자 한다.

\section{II. 결과 중심 성과 관리}

그림 1에서 나타냈듯이 기존의 Project Cycle Management(PCM)가 성과 중심의 설계 및 측정을 강조하고 있다면, 결과 중심의 성과관리 도입 후의 $\mathrm{PCM}$ 은 결과, 즉 사업의 Outcome과 Impact의 달 성 여부에 초점을 맞추고 있다. 이러한 변화는 사업의 기획, 진행 및 평가의 모든 부분에 있어서 반 영되어야 한다. 결과 중심의 성과 관리 단계는 각 $\mathrm{PCM}$ 단계에 따라 다음과 같이 나눠볼 수 있다.

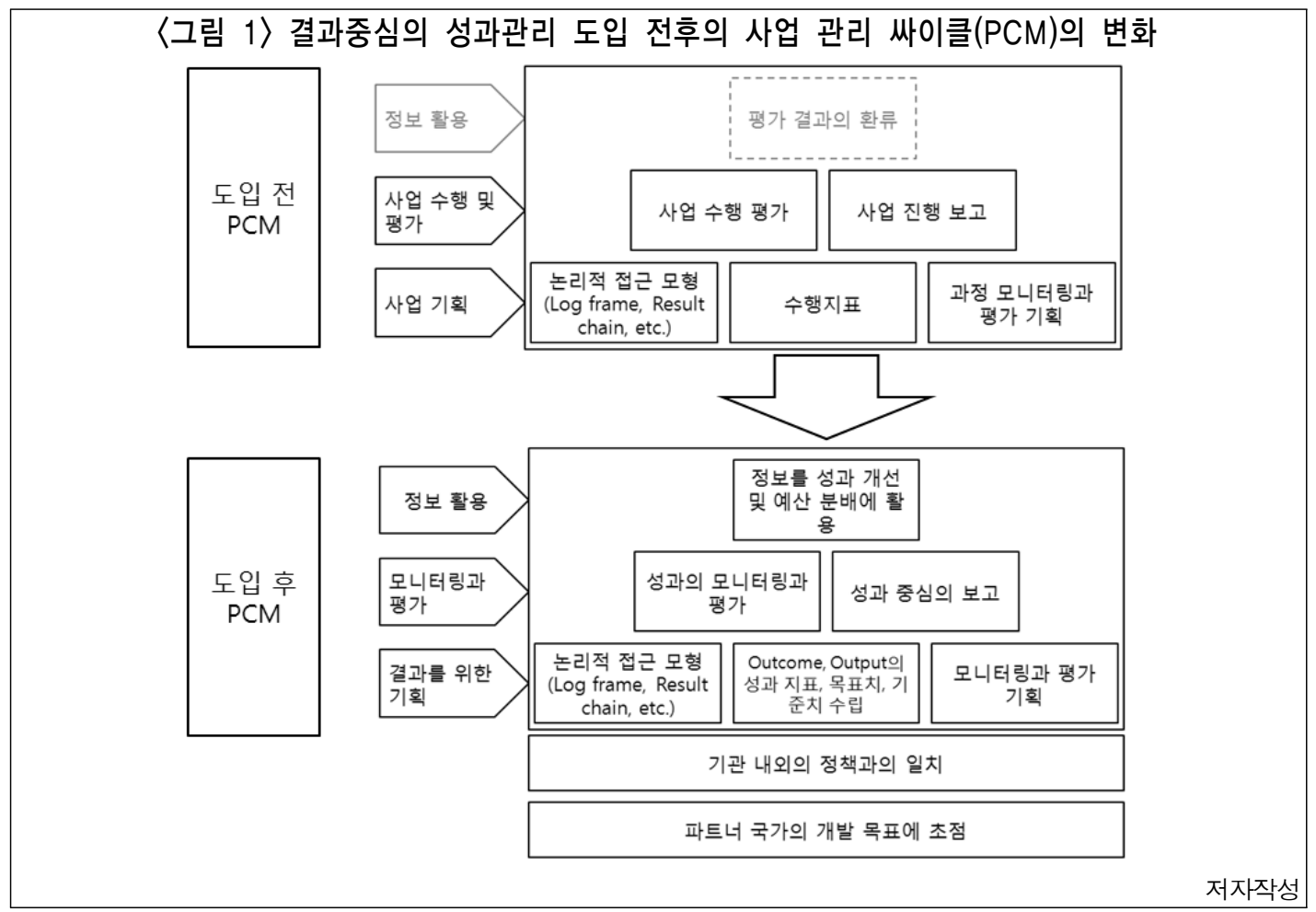




\section{1. 성과를 위한 기획}

기획은 사업의 목표를 정하고 지표와 목표치를 확정하여, 구체적인 실행에 옮기기 위한 제반 준비 를 하는 모든 작업을 뜻한다. 기획단계는 앞으로의 성과 달성에 가장 기초적인 단계이면서 사업의 성 패 여부를 좌우하는 중요한 단계이기도 하다.

결과 중심의 성과관리는 기획단계에서 기존과 달리 기획의 시작이 사업의 결과에서 출발한다. 직 업훈련원 사업을 예로 들어보자(그림 2). 전통적인 과정중심의 성과 관리에서는 기획단계 역시 산출 물인 직업 훈련원생 배출 또는 직업훈련 교육에 초점이 맞추어진다. 그러나 결과 중심의 사업관리를 도입한 후에는 기획과 관리의 초점이 사업의 결과인 취업율과 소득증대에 맞춰지고, 이를 바탕으로 산출물, 활동, 투입물을 결정하는 형태로 사업 기획이 진행된다. 즉, 단지 직업 훈련 시설을 지을 만 한 역량과 강사, 교육 과정이 있기 때문에 사업이 진행되는 것이 아니라, 대상 지역에서 취업률의 상 승을 유발하는 가장 효율적인 방법이 직업 훈련원이기 때문에 사업이 기획되고 진행되는 것이다.

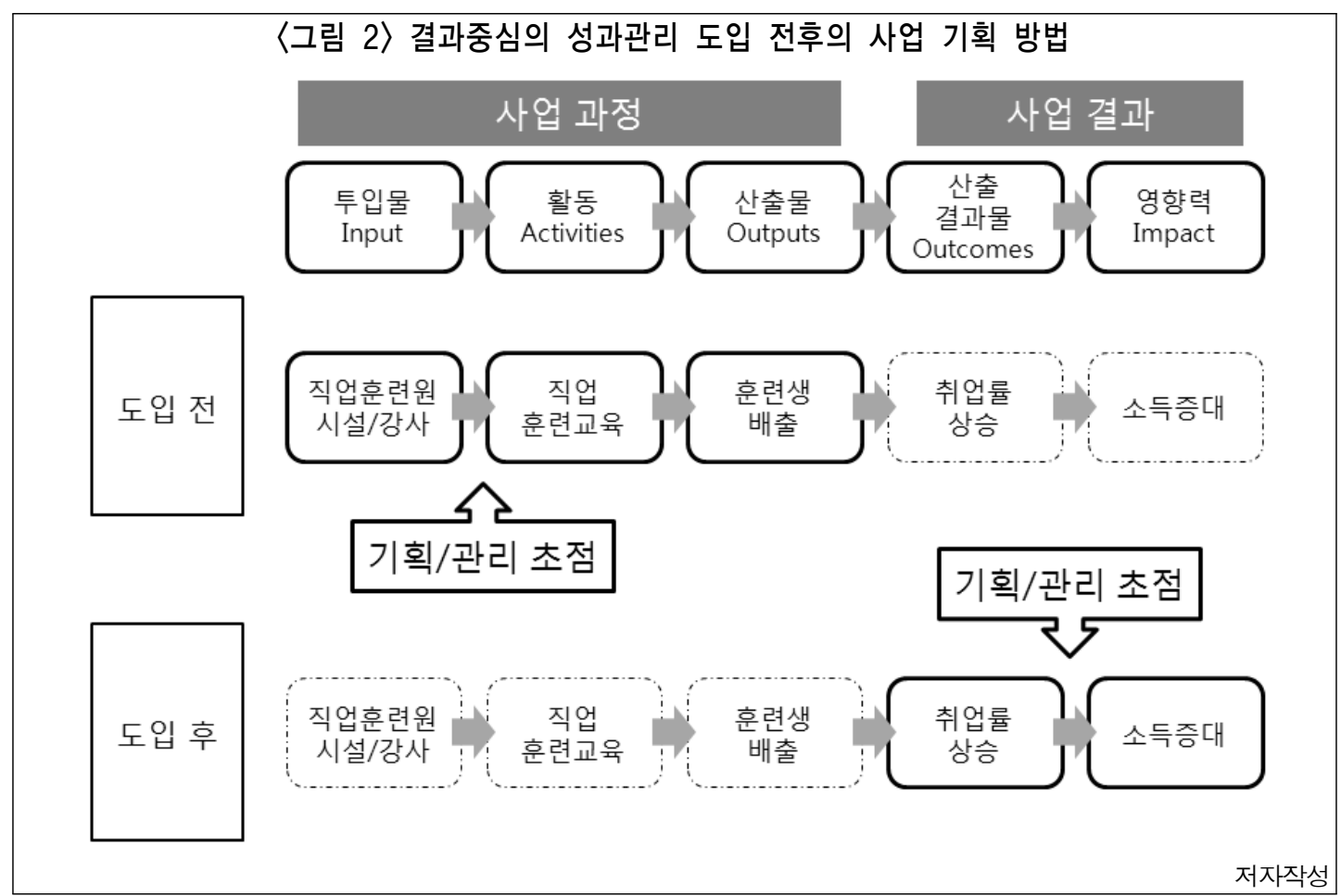




\section{2. 성과 측정: 모니터링과 평가를 통한 정보의 습득}

성과 측정 역시 기존의 성과관리 법이 산출물 단위에서 그친 것과 다르게 결과 중심의 성과관리는 그 초점이 옮겨짐에 따라 그에 대한 모니터링과 평가 방법 역시 변화하고 있다. ${ }^{1)}$

여기에 원조 사업의 현장화와 함께 파트너 국가의 원조에 대한 주인의식 고취 등의 움직임은 이러 한 변화를 더욱 가속화시키고 있다. 대부분의 원조 기구들은 독자적인 평가 전담 부서를 운영하거나 조직에 속해 있던 평가 부서를 독자적인 평가 기구로 독립시키고, 정도의 차이는 있으나 평가에 대한 업무와 권한을 지역 사무소에도 이전하고 있다. ${ }^{2)}$

성과의 측정은 결과 중심의 성과관리에서 매우 중요한 역할을 한다. 사업의 시행자들은 성과 측정 을 통해 사업의 성공이나 실패를 증명하고 검증 받는다. 따라서 관련된 모든 사람이 그 검증 결과에 납득할 수 있을 만한 지표와 측정 방법이 사용되어야 한다. 또한 평가는 사업의 성과 달성 여부가 사 업 설계 자체에서 기인된 것인지 또는 사업의 시행 단계에서 얻어진 결과인지 구분할 수 있는 정보를 제공하여야 한다.

\section{3. 습득한 정보의 의사결정 과정에의 활용}

결과 중심의 성과 관리의 방법이 여타의 성과관리 법과 차별이 되는 특징 중 하나는 결과 정보를 바 탕으로 한 예산 분배 등이 의사 결정에 사용된다는 점이다. 이러한 특징은 기관의 평가 정보 활용 정도 에도 영향을 미쳤다. 이전의 성과관리에서는 기관이 가시적인 채널을 통해 평가 정보의 활용을 보이지 않았다면, 현재의 결과 중심의 성과관리 체제 하에서는 정보가 공유되고 활용되는 방식의 공정성과 투 명성 역시 성과관리의 일부로 인식되고 있다. 따라서 원조 기관들은 특정 리포트 등의 형식을 빌어 기관 의 평가나 모니터링 결과에 대한 대응을 밝히고 있다. 예를 들어 아시아 개발은행(Asian Development Bank, $\mathrm{ADB})$ 의 경우 평가 보고서 결과에 대한 경영진의 대응을 웹 싸이트를 통해 공개하고 있다. ${ }^{3)}$

2011년의 평가 보고서에 의하면 $\mathrm{ADB}$ 경영진은 관리 응답 기록 시스템(Management Action Record System, MARS)이 설립된 2008년도부터 ADB의 독립 평가부서Independent Evaluation Department, IED의 251 개의 권유 사항 중 239 개에 대해 응답을 했고 그 중 217 개에 대해서는 실행

1) Nagao, M.. "Challenging times for evaluation of international development assistance". Evaluation Journal of Australasia, Vol.6. (2006)

2) Foresti, M..et al..A Comparative Study of Evaluation Policies and Practicies in Development Agencies.Série Notes méthodologiques. (AFD, 2007)

3) http://wnw.adb.org/Evaluation/management-response.asp 
에 옮기는데 동의했다. ${ }^{4)}$ 또한 경영진은 2011년 평가 보고서에 대한 응답을 통해, 관리 응답 기록 시 스템이 체계적으로 평가 결과에 대응하는데 도움이 되고 있다고 밝히고 있다.5)

\section{III. 공적 원조 사업에 있어서의 성과관리}

\section{1. 공적 원조 사업에 있어서 결과 중심의 성과 관리의 특성}

공적 원조 기관은 공공기관이면서 원조 기관인 두 가지 특성을 가지고 있다(그림 3). 때문에 여타 의 공공부분의 성과관리 어려움 이외에 원조 사업이 진행되는 현장과의 차이에서 오는 어려움이 더 해진다. 다른 공공기관들의 사업은 대부분 자국 내에서 이루어지며, 따라서 사업 및 성과의 관리에 기관들의 영향력이 큰 편이다. 그러나 공적 원조 사업은 그 사업 현장이 법률이나 인적 자원 등 사업 환경이 매우 다른 수원국이며 또한 원조 형태(프로그램 형 원조 vs. 일반적 제정 지원 등)에 따라 원 조 기관의 통제하에 있지 않은 등 여러 변수로 인한 어려움이 있다.

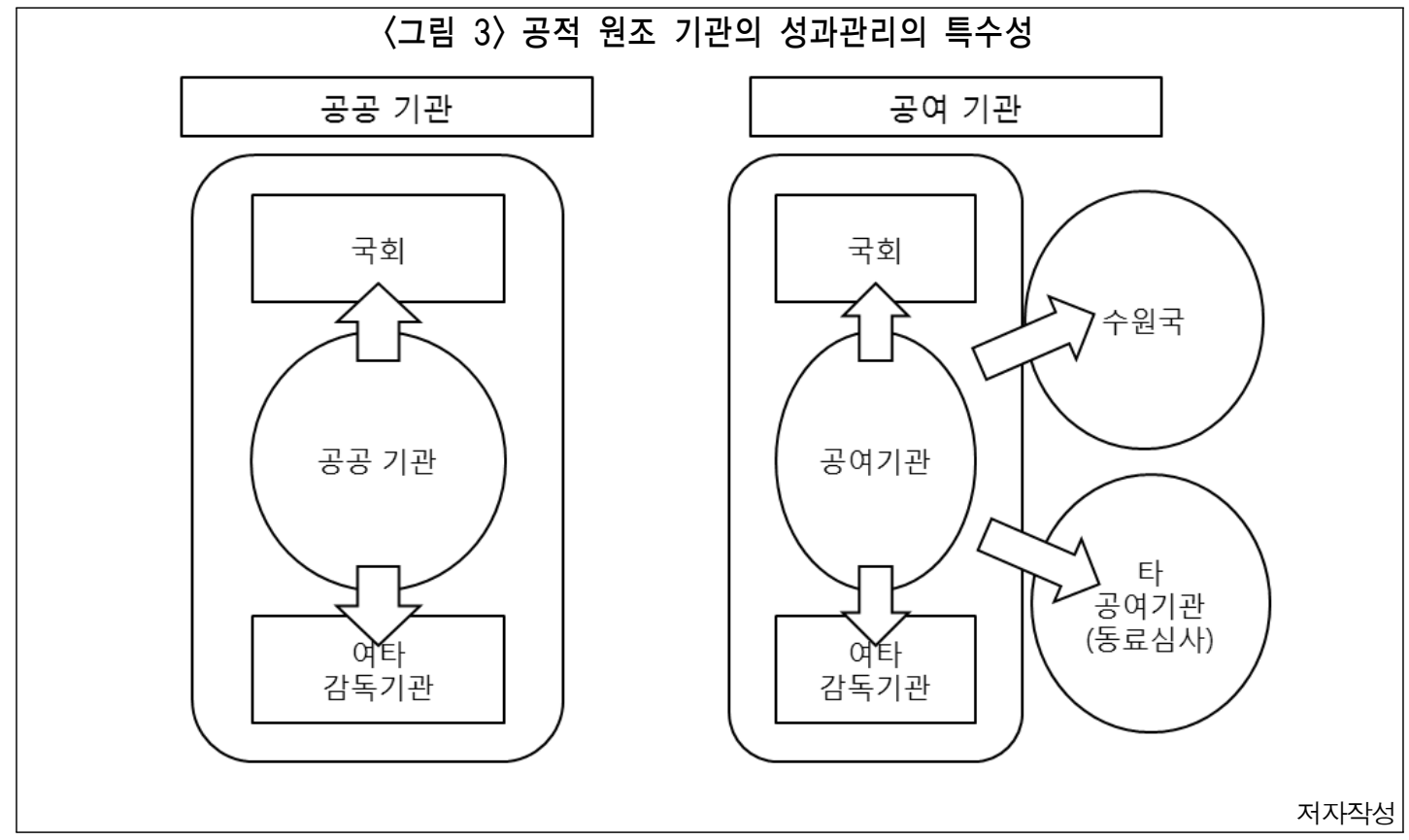

4) ADB Independent Evaluation Department. 2011Annual Evaluation Review, ADB.(ADB, 2011)

5) Asian Development Bank. Management Response to the 2011 Annual Evaluation Review. (ADB, 2011) 


\section{1-1. 공공 기관으로서의 특성}

성과관리의 방법은 일종의 연쇄 반응으로 비유할 수 있다. 즉, 한 조직은 사업을 통해 어떤 성과를 낼 것인지 정의하고, 그 성과를 이루기 위해 투입물의 종류와 수준, 그리고 적합한 활동을 선택하여 산출물을 내고, 그 산출물을 통해 원하는 성과를 이룩한다. 이 과정 동안, 성과의 진행 정도와 달성 정도를 측정하기 위한 모니터링과 평가가 진행 되며, 이러한 과정들은 한 사업이 끝나면 다음 사업으 로 연계되어 진행된다. 그러므로, 성과를 정의하는 첫 단계가 그 이후의 방향을 정하는 가장 중요한 단계이다. 공적 원조사업은 여타의 공공부분 관련 사업과 동일하게 산출이나 결과가 불분명하거나 다차원적인 경우가 많다. 이러한 사업 특성은 '결과'에 대한 정의와 그 의미의 공유를 어렵게 만들 수 있으며 실제로 많은 공공 기관들이 이러한 이유로 사업의 결과 보다는 과정에 치중한 성과관리 제도를 운영해 왔다.

또한 결과의 불분명함은 성과에 대한 정의의 불명확함으로 이어지고, 공공기관 사업의 성격 상 대 부분의 기관 목적과 목적 선언은 다양한 의미로 해석될 수 있기에 공공기관 성과에 대한 정의는 끓임 없이 변화하고 논쟁의 여지를 남긴다. 이러한 주관적인 해석의 가능성은 다중적인 해석과 함께 모든 구성인이 $100 \%$ 동의하는 성과 정의를 이루기 어렵다. 정의가 이루어지지 않으면 다음 작업인 측정 지표의 선정 또한 이루어 지지 않으며, 따라서 단편적이고 전체적인 맥락에 따라 주관적인 요소가 개 입되게 된다. ${ }^{6)}$

예를 들어, 대부분의 공공기관이 공유하는 목표인 '복지 증진 사업'을 들어보자. 구체적인 '복지'에 대한 그림은 개개인 마다 다르며 또한 '증진' 역시 자의적 해석이 얼마든지 가능하다. 따라서 사업의 결과 또는 성과가 명확히 정의 되고 또한 구성원 사이에서 그 정의가 공유되지 않으면 성과 측정 방 법 또한 정의할 수 없게 된다.

\section{1-2. 공여 기관으로서의 특성}

공적 원조기관은 타 공공기관과 달리, 사업 현장이 자국이 아닌 타국, 그리고 대부분 경제적, 정치 적 구조가 취약한 국가가 대부분이다. 결과 중심의 성과관리에 있어서 이러한 현장과 본부 사이의 거 리는 물리적인 거리로서의 장애요소가 아닌 좀 더 근본적인 장애 요인으로 작용한다. 두 정부의 행정 절차나 제정 및 평가 시간표가 서로 맞지 않는 경우, 두 정부간의 구조적인 차이에서 오는 어려움, 취약한 거버넌스 등의 이유로 성과를 정해진 시간 내에 달성 할 수 없는 경우 등 셀 수 없이 많은 장애 요인이 존재한다.

6) Thomas, P.. Performance Measurement, Reporting, Obstacles and Accountability: Recent Trends and Future Directions. (ANU E Press, 2006) 
이러한 문제점 때문에 지금까지 공여기관은 성과를 공여기관의 통제 밖에 있는 결과 보다는 과정, 쉽게 조정할 수 있는 투입물과 산출물 단위에서 측정해 왔으며, 이러한 관리 방법은 근본적인 문제를 해결하기 보다는 회피하는 결과를 가져왔다. ${ }^{7)}$

또한 여타의 공공기관과는 달리 공여기관은 $\mathrm{DAC} / \mathrm{OECD}$ 의 동료평가와 같은 국제 사회의 원조 규 범에 따른 평가를 받는다. 한국과 같이 아직 이러한 규범에 익숙하지 않은 신흥 공여국의 경우 이 규 범을 이해하고, 결과에 대한 정당한 평가를 받기 위해 많은 노력이 필요하다. 또한 국제 규범과 국내 의 성과관리 규범을 얼마나 조화시키느냐에 대한 갈등이 존재할 수 있다.

\section{2. 타 원조기관의 성과관리 동향 및 논점들}

일찍이 OECD/DAC는 2001년 발간된 review 문서를 통해, 회원국들의 공적 개발원조 기관의 성과 관리 현황을 파악하고 효과적인 방법을 모색하는 연구를 계속하고 있다.

기관 운영 도구의 특성상 성과관리 제도는 어떠한 하나의 틀이 모든 공여기관에 맞는 다기 보다 그 기관의 장점과 단점을 파악한 후 기관의 발전 방향에 맞춰 도입하고 변화하는 것이 일반적이다. 즉 기관이 어떠한 형태의 성과관리를 채택하는가는 그 기관의 정치적, 역사적 특성과 불가분의 관계 이며, 따라서 특정 성과관리 시스템이 한 기관에서 잘 활용되었다고 해도 다른 기관에서 동일한 효율 성과 효과성을 기대하기는 어렵다. 지금도 대부분의 원조 기관은 각각의 기관 특성에 맞는 RBM 체제 를 모색하고, 이를 개선해 나가기 위하여 끊임없이 노력하고 있다.

하지만 이러한 성과관리 시스템의 세부 요소와는 관계 없이 KOICA 보다 먼저 성과관리 제도를 도입한 여러 기관들의 사례를 통해 성공적인 성과관리 시스템 도입을 위한 선행 조건들을 몇 가지 찾아 볼 수 있다.

상당히 많은 수의 국가들이 결과 중심의 성과관리 시스템을 도입하는 배경에는 정치적인 압력 등의 외 압과 위기 의식이 있다. ${ }^{8)} \mathrm{OECD}$ 국가들을 중심으로 일어난 결과 중심의 성과관리 시스템 도입 움직임은 경기침체로 인해 줄어든 제정에 비해 과도한 행정 비용을 줄이고, 국민들의 불신을 종식시키기 위해 시 작되었으며9), 이는 원조 피로 등의 문제점을 안고 있는 공적 원조 기관에서도 마찬가지이다. ${ }^{10)}$

여러 문서들을 종합해 보면, 성공적인 결과 중심의 성과관리 제도 도입을 위해 제일 먼저 선행되 어야 하는 조건으로 운영자진의 적극적인 추진 의지를 들고 있다. 또한 성과측정의 방법인 사업 평가

7) Flint, M.. Easier Said than done: A review of results-based management in multilateral development institutions. (2003)

8) ADB. Managing for Development Results in the Asian Development Bank: A Preliminary Assessment. (Asian Development Bank, 2007)

9) 고영선 외, 『공공부분의 성과관리』, (한국개발연구원, 2004)

10) ADB. Managing for Development Results in the Asian Development Bank: A Preliminary Assessment. (Asian Development Bank, 2007) 
및 모니터링, 친화적 조직 문화를 유도하는 문화적 변화와 함께, 성과 보고 및 측정을 통한 지식의 축적과 성과 정보를 이용한 사업 방식의 개선 등의 제도적인 변화가 필요하다. 이를 효과적으로 이룩 하기 위해서는 효율적이고 정확한 성과 측정 방법과 함께 그 정보를 시기 적절하게 제공할 수 있도록 하는 전산망 등의 기술적 역량이 뒷받침 되어야 한다. ${ }^{11) 12) 13)}$

\section{IV. 프랑스의 ADF의 성과관리 사례}

그림 4에서 보이는 것과 같이, 프랑스는 우리나라와 마찬 가지로 원조 정책 입안 기관과 원조 수행 기관이 분리된 형태의 공적 원조 운영체제를 가지고 있다14). 또한 우리나라가 원조 선진화 방안으로 준비하고 있는 조절위원회를 통해 각 기관의 원조 일원화 방식을 시도하고 있는 나라이다. 따라서 프 랑스 원조기구의 성과관리 사례를 통해 같은 기관 형태를 취하고 있는KOICA의 성과관리에 대한 시사 점을 도출해보고자 한다.

\section{〈그림 4〉ODA 시행 구조: 프랑스와 대한민국}

\section{프랑스}
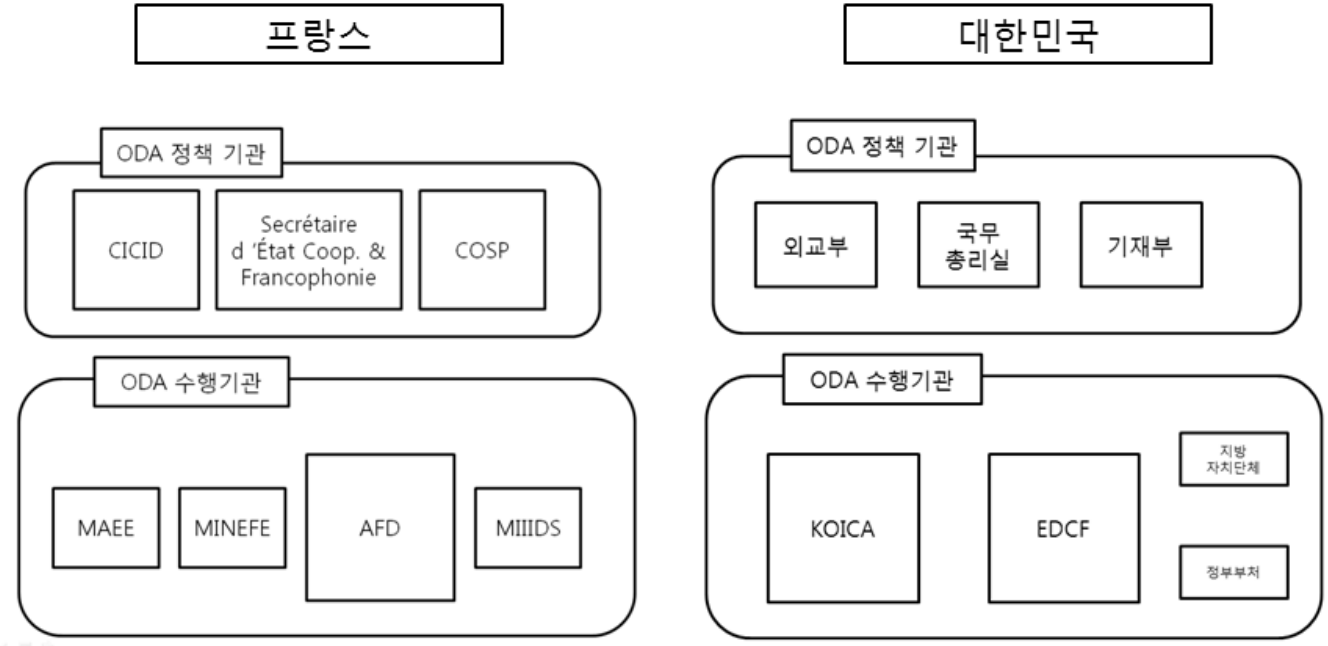

저자작성

11) Hailey, J..et al..Measuring Success: Issues in performance Management. Occasional papers series No:44 . (INTRAC, 2004)

12) Mayne, J.. "Challenges and Lessons in Implementing Results-based management". Evaluation, vol.13. (2007)

13) Binnendijk, A. Result based management in the development co-operation agencies: a review of experience. (OECD/DAC, 2001)

14) OECD/DAC, Managing Aid: Practices of DAC Member Countries. (OECD/DAC, 2009) 


\section{1. $\mathrm{ADF}$ 개요}

Agence Fran aise de Développement, $\mathrm{ADF}$ 는 프랑스의 공적 원조기관이다. 해외 원조 대표기구로는 $\mathrm{ADF}$ 이외에도 Directorate General for Global Affairs, Development and Partnerships (Ministry of Foreign and European Affairs), Treasury and Economic Policy General Directorate (Ministry of the Economy, Finance, and Employment)가 있으며, 이 외에도 여러 단체와 기구들 그리고 각각의 목적 등이 복잡하게 얽혀있는 구조를 가지고 있다(그림 5). 최근 구조조정을 통해 $\mathrm{AFD}$ 가 대표적인 국가 공적 원조 기구로써 새천년 개발목표의 달성에 주력하고, 나머지 정부부서들 이 전략과 목표를 설정하는 형태로 개편되었다. ${ }^{15) 16)}$

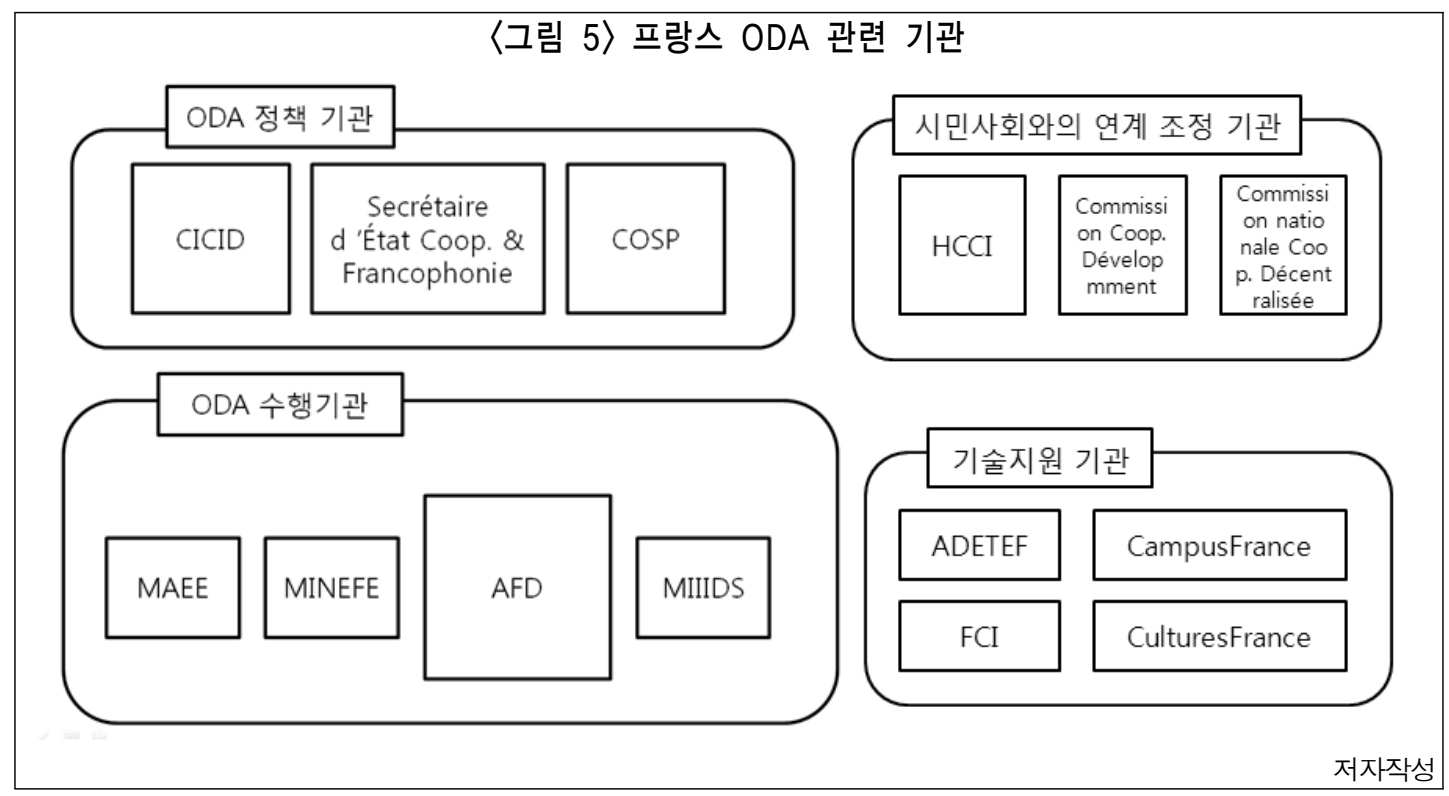

\section{2. $\mathrm{AFD}$ 의 사업 성과 관리}

$\mathrm{AFD}$ 의 성과관리는 양자 원조기관의 성과관리의 근본적인 문제인 국내와 국외의 책무성에 대한 조 화를 이루고 있는 것으로 평가 받고 있다. ${ }^{17)} \mathrm{AFD}$ 는 근본이 되는 프랑스 정부의 성과관리 법인 "Loi Organique Relative aux Lois de Finances" (LOLF)의 규칙과 국제 사회 규범과 파트너국 국민에 대한 책무성의 균형을 유지하기 위한 노력을 기울이고 있다.

15) OECD/DAC, Peer review: France.. (OECD/DAC, 2008)

16) http://www. objectivo2015.org/europe/documents/WAfr09.pdf

17) OECD/DAC, "Part 1. MfDR Concepts, Tools and Principles". Sourcebook on Emerging Good Practice in Managing for Development Results, $1^{\text {st }}$ ed.(OECD/DAC,2006) 


\section{2-1. 사업 단계에 따른 성과관리}

\section{2-1-1. 사업 형성, 설계 및 시행의 성과관리}

그림 6은 $\mathrm{AFD}$ 는 사업의 형성과 설계, 시행 단계를 나타내고 있다. $\mathrm{AFD}$ 는 모든 사업 관리 싸이클 단 계에 있어서 사업을 직접 시행하는 주체와 $\mathrm{AFD}$ 의 역할을 확실히 구분하고 있다. ${ }^{18)}$ 사업은 시행주체 즉, 사업을 필요로 하는 파트너가 구상을 하고, $\mathrm{AFD}$ 는 이에 대한 심사 및 지원을 담당하고 있다. $\mathrm{AFD}$ 는 또한 사업의 심사와 지원에 있어서 각각의 사업들을 각개의 사업으로 보기 보다, 원조 사업의 효율 성과 원조 효과성을 높이기 위해 프랑스 원조 정책 기구와의 협의를 통해 중장기 기획을 구성하고 그 기획에 따른 큰 범위 내에서 연관성 있게 진행시키도록 노력한다.

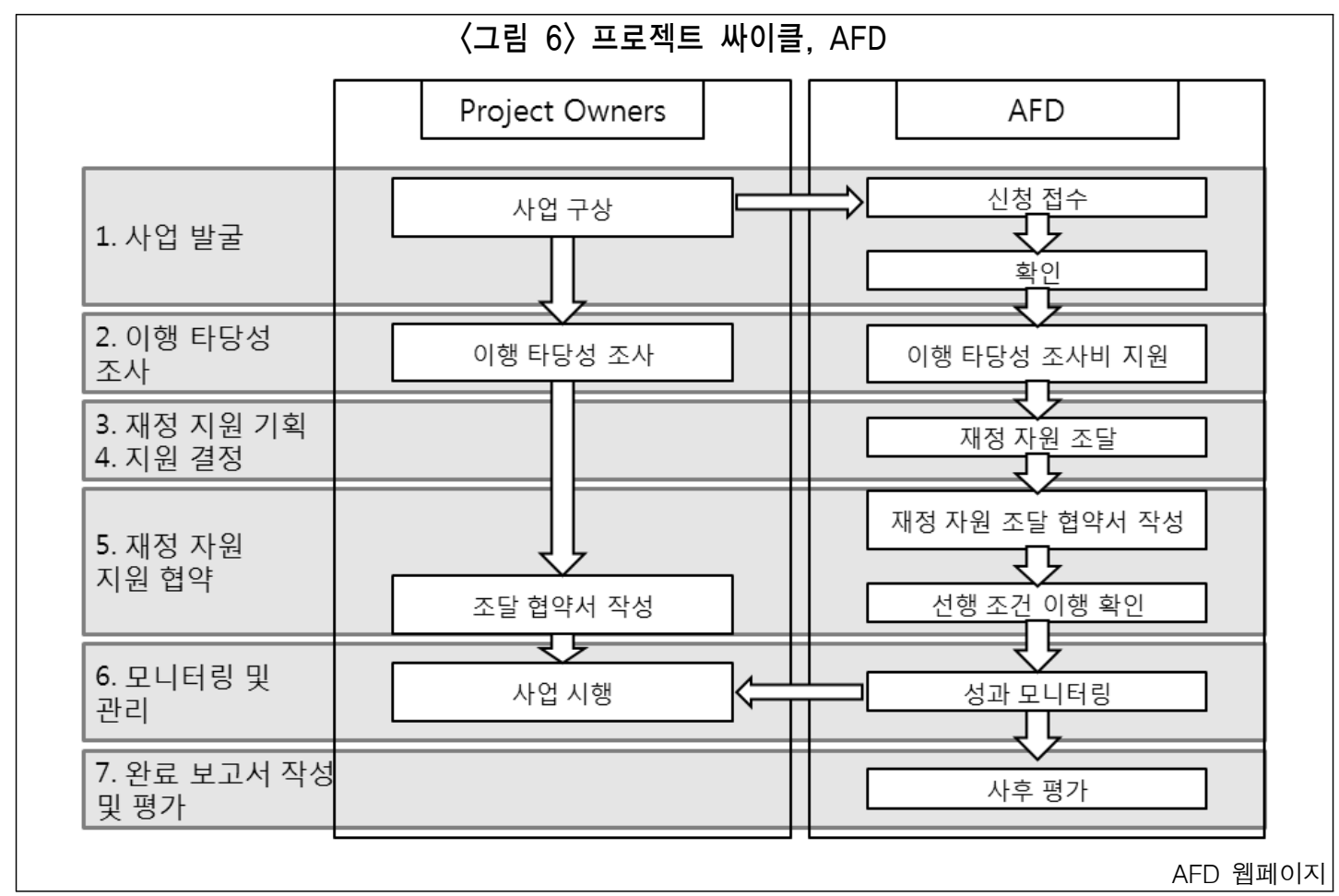

이러한 역할 구분은 사업의 진행 파트너인 사업 시행자(파트너국)와 $\mathrm{AFD}$ 직원 사이의 권한 및 책임 에 대한 소재를 분명히 하며, 성과 관리를 원활히 진행할 수 있게 해준다.

\section{2-1-2. 사업 평가}

프랑스 원조 관련 기구들은 각각 독립적인 평가 기구를 운영하고 있으며 $\mathrm{AFD}$ 역시 예외는 아니

18) http://www.afd.fr/lang/en/home 
다. $\mathrm{AFD}$ 의 평가는 평가와 지식 발달 부서Evaluation and Knowledge Development Unit, EKDU에서 담당하고 있으며 그 설립 목적은 다음과 같다.

1) 과거의 경험을 바탕으로 하여 앞으로의 원조 정책, 프로그램 및 프로젝트를 향상시킨다.

2) 책임성의 근거를 제공한다.

이러한 취지 아래 $\mathrm{EKDU}$ 는 $\mathrm{AFD}$ 의 사업 평가 전반에 걸친 가이드 라인 및 기술 지원 등을 제공하며, 평가의 품질을 관리한다. 또한AFD의 후원 하에 이루어진 프로그램들에 대한 영향 분석이나, 전략에 대한 평가를 관리한다. 또한 필요 시 특정 섹터 및 프로그램 등에 대한 메타 평가meta-evaluations를 시행하여 지식을 축적하고 공유하고 있다. ${ }^{19)}$

또한 그림 7에서와 같이, 성과 평가의 보고 체계를 확실히 하여 사업 성과 평가 결과가 기관의 성과와 연계되고, 더 나아가 앞으로의 정책 방향을 결정하는 데 참고할 수 있는 근거 자료로 활용하고 있다.

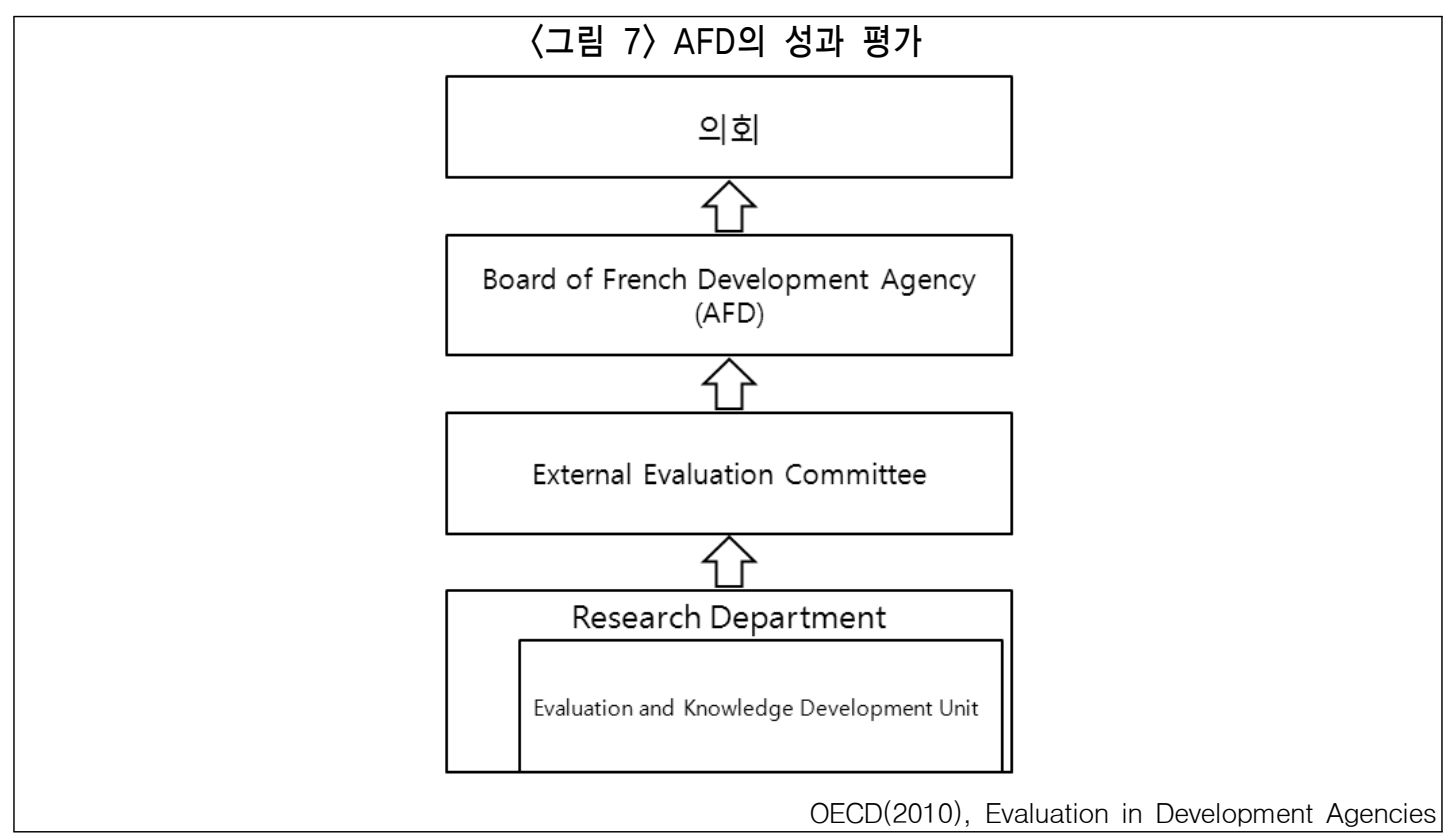

\section{2-2. 국내와 국제 사회에서의 책임성과 투명성 보장 노력}

프랑스 외교부의 공적 원조 기본 방향 문서인 개발 협력: 프랑스의 비젼 'Development Cooperation: A French vision -Framework document'은 공적 원조 사업의 평가를 통한 결과 측정

19) http://www.afd.fr/lang/en/home 
은 프랑스 의회와 국민들에 대한 의무일 뿐만 아니라, 사업의 협력자이며 소유자인 파트너 국가의 국 민에게도 중요한 의무로 규정하고 있다. ${ }^{20)}$ 이러한 기본 지침은 평가 보고서나 평가 가이드라인 등에 도 포함되어 있다. $\mathrm{AFD}$ 는 자신들이 시행한 사업의 평가 보고서를 웹 싸이트 등을 통해 공유하고 있으 며 또한 전산 시스템인 SIS를 운영하여 자료를 보존하고 효율적으로 활용할 수 있도록 하고 있다.

\section{2-3. 성과 표준 지표의 사용}

$\mathrm{AFD}$ 의 사업은 섹터 별로 지정된 표준 지표Aggregate Indicators를 이용하여 성과를 측정하도록 되어 있다 (그림 8). 파트너 국가 등 $\mathrm{AFD}$ 의 후원을 받은 사업의 시행 주체는 반드시 $3 \sim 4$ 개의 표준 지표를 사용해야 한다.

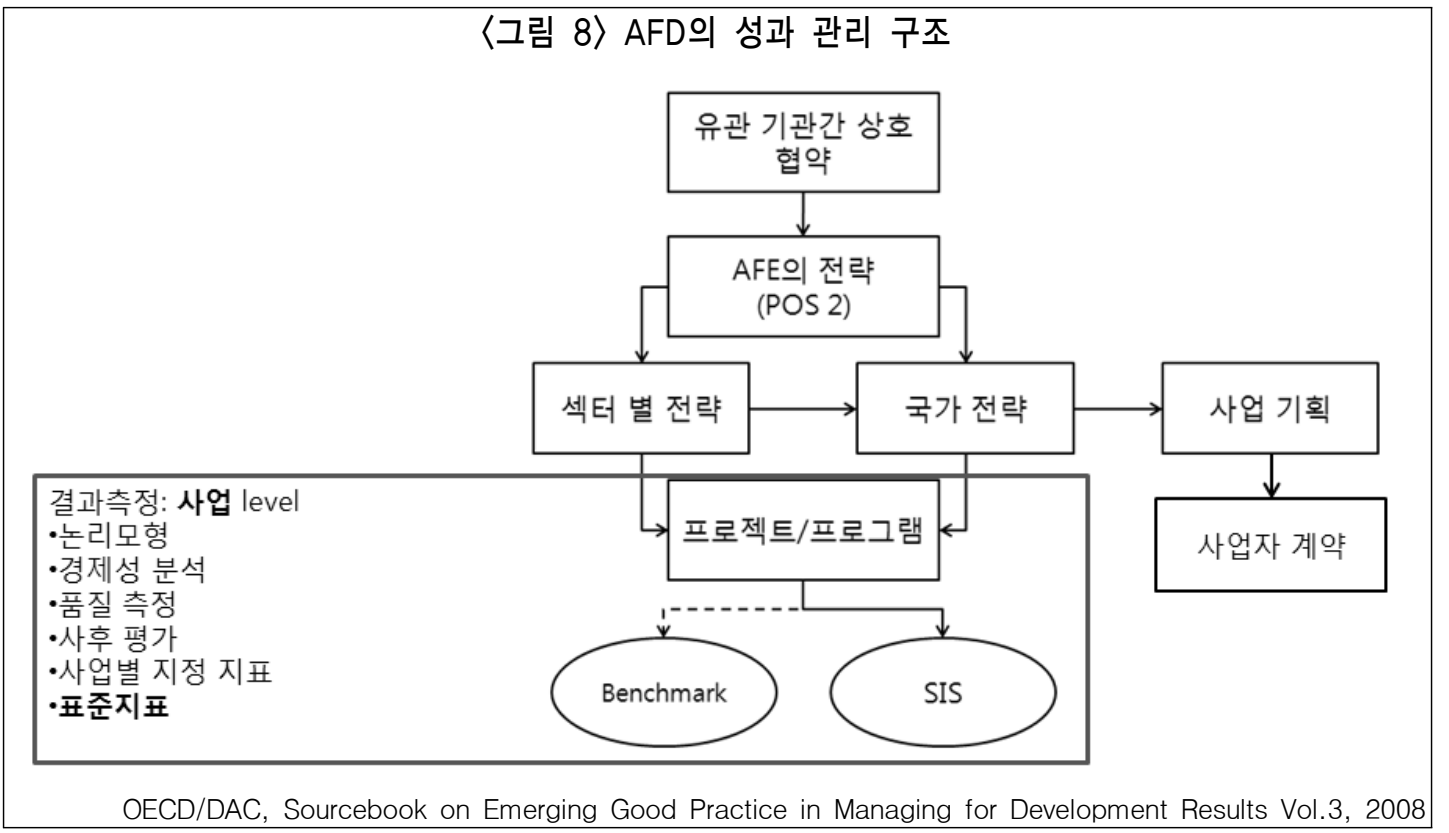

$\mathrm{AFD}$ 은 58개의 표준지표를 사용하고 있으며 이 지표가 어떻게 측정 되어야 하는지 자세히 밝힌 매 뉴얼을 지급하고 측정 방법을 익히기 위한 훈련 역시 제공하고 있다. ${ }^{21) 22)}$

이렇게 표준화된 지표를 표준화된 방법으로 측정했을 때 기관의 섹터별 성과 정도를 쉽게 파악할 수

20) Ministry of Foreign and European Affairs, Government of France. Development Cooperation: A French vision Framework document. (Government of France, 2011)

21) AFD. Guide d'utilisation des indicateurs agregeables dans les etats etrangers A L'AFD. (AFD, 2007)

22) OECD/DAC, "Case Studies at Institutional Level". Sourcebook on Emerging Good Practice in Managing for Development Results, $.3^{\text {rd }}$ ed. (OECD/DAC,2008) 
있다는 것을 장점으로 들 수 있다. 예를 들어 같은 구성의 초등학교 교육 사업을 세네갈과 아이티에서 시행한 경우 이 두 사업의 성과가 동일한 방법으로 측정 되고, 그 성과는 이 후 교육 섹터의 성과로 쉽 게 더해질 수 있다.

또한 이러한 표준지표가 가져올 수 있는 경직성을 피하고 표준 지표가 사업의 특성을 충분히 반영하 지 못할 때를 대비하여 사업별로 특수성을 반영하기 위한 사업별 지표의 사용 역시 권장하고 있다.

\section{V. 결론 및 제언}

원조 사업의 성과관리는 20 년 넘게 진행되어 왔으며, 최근 파리선언의 5 대 원칙 중 하나이며 다른 4 대 원칙을 뒷받침하는 개발 결과를 위한 관리(Management for Development Results)로 그 초점이 모이 고 있다. 공공 기관에 있어서 성과 관리는 1980 년대와 90 년대를 거치며 중요성의 인식과 함께 서구 사 회를 중심으로 공공 제도 혁신의 중심으로 떠올랐고, 현재 대부분의 $\mathrm{OECD}$ 국가의 공공기관에서 다양 한 형태의 성과관리 시스템을 운영 중이다. 그러나 성과관리 시스템의 도입은 말처럼 쉬운 일이 아니 다. 특히 원조 사업 부분의 성과관리 제도는 공공제도 특성에서 오는 장애 요소인 결과 정의의 어려움 외에도 실직적 사업 현장과 사업 원조 기관이 각기 다른 국가에 속해 있는 등의 특수성에 의해 그 도입 과 시행에 있어서 여러 가지 어려움을 겪고 있다. 이는 한국의 공적 개발 원조(Official Development $\mathrm{Aid}, \mathrm{ODA}$ )를 수행하고 있는 한국 국제 협력단(이하 KOICA) 역시 마찬가지로 안고 있는 어려움이다.

사업의 결과 중심의 성과 관리는 사업의 어느 한 단계에서가 아닌 사업의 발굴부터 평가, 평가 이 후의 정보 이용에 이르기까지의 모든 단계에서 지속적으로 진행되어야 한다. 따라서 결과 중심의 성 과관리 제도의 정착을 위해서는 조직의 문화 변화가 선행되어야 한다. 이러한 문화의 변화는 강력한 지도층의 의지와 함께 성과를 측정하고 공유하기 위한 기술적인 개선이 동반될 때에만 현실적이고 효 과적인 성과관리 시스템의 구축으로 이어질 수 있다.

$\mathrm{KOICA}$ 의 사업 성과관리 역량은 그 분야에 따라 차이를 보이고 있다. 사업 평가의 독립성과 투명 성에 대해 $\mathrm{KOICA}$ 는 다른 공여 기관과 비교하여 크게 뒤쳐지지 않은 편이다. 여러 공여 기관들과 마 찬가지로 $\mathrm{KOICA}$ 역시 사업의 평가를 전담하는 평가실을 운영하고 있으며, 평가를 직접 시행하기 보 다는 외부 전문가를 고용하여 그 독립성을 높이고 있다. 또한 모든 KOICA의 사업 평가 보고서는 $\mathrm{AFD}$ 와 마찬가지로 공개되어 있으며, 이용을 원하는 경우 쉽게 접근할 수 있어 사업의 진행과 결과에 대해 책임성과 투명성을 보장하려는 노력을 끊임없이 기울이고 있다. 
그러나 성과 측정 면에 있어서는 KOICA는 $\mathrm{AFD}$ 가 이용하는 것과 같은 지정된 표준 지표 목록이나 그 측정법을 지정한 매뉴얼은 아직 갖추지 못하고 있다. 따라서 같은 섹터의 사업이라 할지라도 때로 는 그 성과를 비교하는 등의 분석이 불가능 하며, 기관의 전체 성과로 환산하는 데에도 많은 어려움을 겪고 있다. 이러한 점을 개선 위해서 현재 KOICA는 표준 성과 지표를 지정하기 위한 연구 중에 있다.

물론 $\mathrm{AFD}$ 의 제도가 그대로 $\mathrm{KOICA}$ 에도 적용될 수는 없다. 그러나 $\mathrm{AFD}$ 의 체계적인 사업의 수립 방법, 국내와 국제 사회에서의 책임성과 투명성 보장 노력, 표준 성과 지표 등을 통한 성과 관리 등 은 앞으로 KOICA가 사업 성과관리를 선진화하는데 도움이 될 것으로 사료된다. 


\section{참고문헌}

\section{1. 국내문헌}

고영선 외, 『공공부분의 성과관리』, (한국개발연구원, 2004)

\section{2. 국외문헌}

Asian Development Bank. Management Response to the 2011 Annual Evaluation Review. (ADB, 2011).

ADB. Managing for Development Results in the Asian Development Bank: A Preliminary Assessment. (Asian Development Bank, 2007).

ADB Independent Evaluation Department. 2011 Annual Evaluation Review, ADB. (ADB, 2011).

AFD. Guide d'utilisation des indicateurs agregeables dans les etats etrangers $A$ L'AFD. (AFD, 2007).

Binnendijk, A.. Result based management in the development co-operation agencies: a review of experience. (OECD/DAC, 2001).

Flint, M.. Easier Said than done: A review of results-based management in multilateral development institutions. (2003).

Foresti, M.. et al..A Comparative Study of Evaluation Policies and Practicies in Development Agencies. Série Notes méthodologiques. (AFD, 2007).

Hailey, J..et al.. Measuring Success: Issues in performance Management. Occasional papers series No:44. (INTRAC, 2004).

Mayne, J. "Challenges and Lessons in Implementing Results-based management". Evaluation, vol.13. (2007).

Ministry of Foreign and European Affairs, Government of France. Development Cooperation: A French vision -Framework document. (Government of France, 2011).

Nagao, M. "Challenging times for evaluation of international development assistance”. Evaluation Journal of Australasia, Vol.6. (2006). 
OECD/DAC, Paris Declaration on Aid Effectiveness \& Accra Agenda for Action. (OECD/DAC, 2005/2008).

OECD/DAC, "Part 1. MfDR Concepts, Tools and Principles". Sourcebook on Emerging. Good Practice in Managing for Development Results, $1^{\text {st }}$ ed. (OECD/DAC, 2006).

OECD/DAC, "Case Studies at Institutional Level". Sourcebook on Emerging Good Practice in Managing for Development Results, $3^{\text {rd }}$ ed. (OECD/DAC, 2008). OECD/DAC, Peer review: France.. (OECD/DAC, 2008). OECD/DAC, Managing Aid: Practices of DAC Member Countries. (OECD/DAC, 2009). OECD/DAC, Evaluation in Development Agencies. (OECD/DAC, 2010).

Thomas, P.. Performance Measurement, Reporting, Obstacles and Accountability: Recent Trends and Future Directions. (ANU E Press, 2006).

\section{3. 인터넷 자료}

ADB Management's Responses to Evaluation Studies 웹싸이트 http://www.adb.org/Evaluation /management-response.asp 검색일: 2011년 8월 14일 $\mathrm{AFD}$ 공식 웹싸이트 http://www.afd.fr/lang/en/home 검색일: 2011년 10월 6일 End poverty by 2015 campaign, What About France? http://www.objectivo2015.org/europe /documents/WAfr09.pdf 검색일: 2011년 11월 8일 